\title{
Industrial Dye Process Monitoring using Wireless Node Communication
}

\author{
N. Mahesh \\ (Assistant Professor) \\ Department of Electronics and Instrumentation Engineering \\ Kongu Engineering College \\ Erode,Tamilnadu, India \\ T. N. Aneruddh \\ (Under Graduate Student) \\ Department of Electronics and Instrumentation Engineering \\ Kongu Engineering College \\ Erode,Tamilnadu, India
}

\author{
A. Abu Thahir \\ (Under Graduate Student) \\ Department of Electronics and Instrumentation Engineering \\ Kongu Engineering College \\ Erode,Tamilnadu, India \\ R. Elakkiya \\ (Under Graduate Student) \\ Department of Electronics and Instrumentation Engineering \\ Kongu Engineering College \\ Erode,Tamilnadu, India
}

\author{
M. Indumathi \\ (Under Graduate Student) \\ Department of Electronics and Instrumentation Engineering \\ Kongu Engineering College \\ Erode,Tamilnadu, India
}

\begin{abstract}
Dyeing is a process in which color is transferred to a finished fabric material to add permanent and long-lasting color. The dye is generally applied in two ways. One is by steaming and other is by soaking in cold water. Typically in steaming process, the steam is passed to provide rapid heating which fixes the dye molecules from the thickener film to the fibre within a reasonable time. The temperature of the steam must be maintained within a range. The proper transfer of dye color can be achieved by maintaining the $\mathrm{pH}$. If $\mathrm{pH}$ level tends to exceed the span then an uneven spread of dye is observed on the fabric cloth. Currently monitoring of these parameters in small firms are done through wired networks, which can sometime cause communication failures where even in some cases the problem remain unidentified. By using Wireless Node Communications, the main process parameters are monitored and the unidentified errors in the current method are eliminated in a highly reliable efficient way.
\end{abstract}

Keywords: Dyeing; wireless node communication; steaming process; networks

\section{INTRODUCTION}

Dyeing is regularly done in an uncommon arrangement containing colors and certain synthetic material. Subsequent to dyeing, dye molecules have whole Chemical bond with fiber particles. The temperature and $\mathrm{pH}$ controlling are two key factors in dyeing. In businesses dyeing procedure is of two different ways. In first technique the texture which is going for dyeing procedure is washed by blend of water and wet-oil then

$\mathrm{pH}$ of that blend is estimated. In the event that if $\mathrm{pH}$ isn't in a range, at that point buffer is included into the blend, again the texture is washed with that blend. Washing procedure is regular for both strategy. In the wake of washing texture is absorbed color for couple of hours during which steam is permitted to pass on texture for appropriate fixing of color. In second technique steam along with color is passed on to the washed texture

In a typical fixation process, the steam provides fast warming that achieves the exchange of dye atoms from the thickener film to the fiber within a sensible time. In this steaming procedure it is necessary to keep up a temperature range. Temperature range relies on the kind of texture and sort of color utilized in the procedure. Similarly in washing process $\mathrm{pH}$ is to be monitored. Controlling the $\mathrm{pH}$ is significant in color shower since its influence dyeing cycle. $\mathrm{pH}$ impacts the take-up of dye within the texture. In instance of corrosive dyeing a low $\mathrm{pH}$ frames a hydrogen bond that join color atoms to fabric. In some exceptional dyes, initial bath conditions is to keep up $\mathrm{pH}$ from 6.5 to 7.

\section{LITERATURE SURVEY}

If a typical textile is washed after printing and drying, a substantial part of the color is removed. Hence a fixation process is necessary. Complete fixation can solely be achieved, however after the removal of unfixed dye, thickening and secondary chemicals in a subsequent washing process is normally required. The efficiency with which these processes of washing and fixation are carried out is vitally important, to both the quality and the cost of the prints. The ratio of faults in the final product that are introduced at this stage can be dangerously high.

Fixation of printed clothes is usually done by steaming processes, the steam providing the moisture and rapid heating that brings about the transfer of dye molecules from the thickener film to the fiber within a reasonable time. Historically, the process of developing printed moderants was known as 'ageing' which took a long time, as the term defines. Printed fabric was draped over poles and left in a room with a warm and humid atmosphere for some days, in order to allow the processes of diffusion and chemical reaction to occur. This can lead to confusion, so the two terms can be used interchangeably. The time and conditions for fixation in steam vary with the properties of the dyes and fibers used, ranging from $10 \mathrm{~s}$ to $60 \mathrm{~min}$ in steam at 60 to $100 \mathrm{C}$. Technical and economic factors have encouraged the use of higher 
temperatures for shorter duration, and the change from batch wise to continuous processes. A constant feature in the design of all printing steamers, as distinct from steamers for other textile processes, is the need to prevent the marking-off of printed color on to pale-colored areas.

Steam can be a convenient source of both water and heat as both are transferred rapidly and uniformly over the surface areas of printed fabric entering a steam chamber. Since we have seen that steam may be wet or dry, saturated or superheated, and the conditions of use must be chosen and maintained.

The essential requirements in all print fixation processes using steam are listed below

- The pick-up of enough water to swell the thickener film, but not so much as to cause the print to spread.

- Dispersion and solution of the dye, and production of a liquid medium through which the dye can diffuse to the fibre surface.

- Absorption of water by fibres such as cotton, nylon and wool, which must be swollen to allow penetration of dye.

- Raising the temperature to a level that accelerates the processes of diffusion, especially into the fibre.

In some cases steam can satisfy all the requirements but, as in all coloration processes, secondary chemicals are introduced to assist dye solution and diffusion, or to make the process less critically dependent on the maintenance of ideal conditions.

\section{OBJECTIVE}

The Dye Industries require a quite often monitoring of the process parameters henceforth to make sure that the operating conditions are under control so that the dye sticks evenly throughout the fabric. Our main objective of our project is to monitor and control the main process parameters (Temperature \& $\mathrm{pH}$ ) from a common domain for all the dyeing process carried out at different sectors within the firm.

\section{EXISTING METHOD}

In many small dyeing mills around Erode and Tiruppur, the main process parameters are monitored manually. An operator is involved in monitoring the $\mathrm{pH}$ from the sample water which is mixed with the wetting-oil and used for washing the clothes at the beginning of the process after the clothes are washed to pure white colour, the textile is sent to the next sector for dyeing process. A continuous stream of water mixed with exact ratio of colour dyes is passed over the textiles and required chemicals are added to maintain the quality of dyes.

The speed and quality of dyeing highly depends upon the attachment of the dye to the fibre. There are six theories to predict this attachment: physical theory, chemical theory, physico-chemical theory, fibre-complex theory, solid solution theory and mechanical or pigment theory. During dye fixation, steam is continuously passed through the fabric so that the dye gets fixed to the fabric perfectly. To achieve this, the operator must keep monitoring the steam and maintaining it at $60-100 \mathrm{C}$ for effective fixation. The drawback is that the operator must keep monitoring both the process operating at different sectors of the firm, Thus they require a common monitoring and control domain from which all the process parameters for all different textiles are monitored by the operator.

\section{PROPOSED METHOD}

The block diagram for the proposed method is shown in figure 1 which includes Node MCU, cooler fan, pump, temperature control unit, $\mathrm{pH}$ control unit, monitoring section.

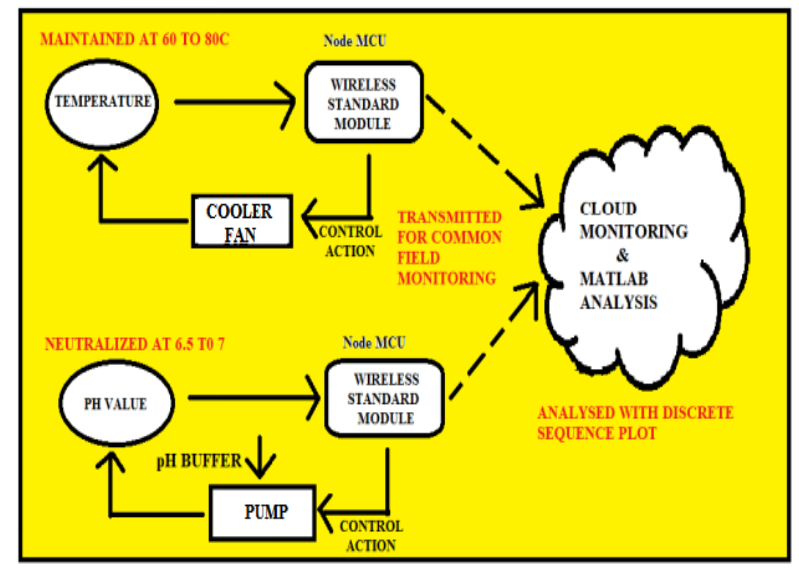

Fig 1. General block diagram

$\mathrm{pH}$ is measured by using $\mathrm{pH}$ electrode which is interfaced with NodeMCU. The obtained data is continuously uploaded to the cloud. A proper action is taken by the pump when the $\mathrm{pH}$ is not within the range. Pump tends to add buffer into the solution in order to neutralize the $\mathrm{pH}$. Simultaneously temperature is measured from the steam by using a temperature sensor which is then uploaded to the cloud by wifi module. Similarly when the temperature is not within a selected range, a control action is to be incorporated by the cooler fan to reduce the temperature.

\section{A. Design For Temperature Control Loop}

The circuit diagram for controlling temperature at a specific range is shown in the figure 2

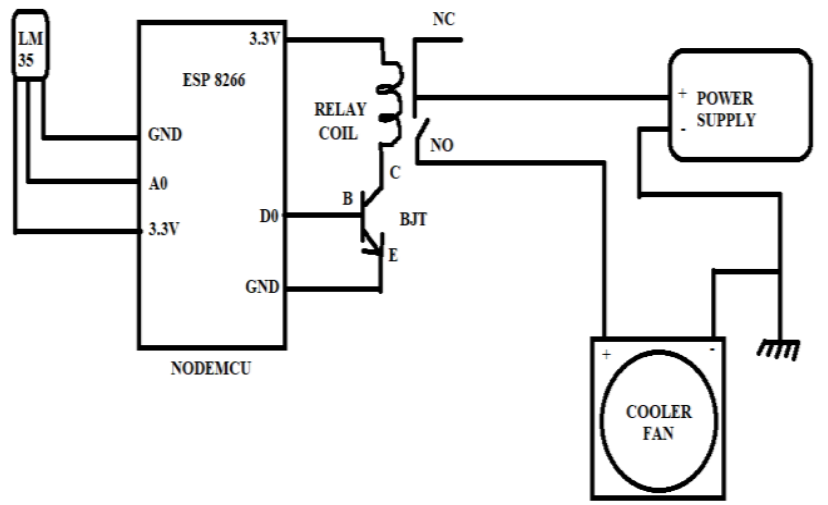

Fig 2. Circuit Diagram for Temperature Control

The Digital output pin D0 is made high when the temperature exceeds some value. A Transistor (BJT) acts as a switch here, the base of the BJT is directly connected to the D0 pin of the NodeMCU. In the collector side a Electromechanical relay is connected by a general supply 
voltage of 3.3V from MCU and the ground terminal connected to the collector.

Now whenever D0 is high there is a link between collector and emitter terminal and thus the ground is connected to the GND pin of MCU. So this excites the Relay coil and on the other hand the movable contact of the relay (i e COM) is given a battery supply of $9 \mathrm{~V}$ to drive a cooler fan. In the Normally Open terminal the Cooler fan is connected. There is normally a small lag after the LM35 senses the temperature and before the cooler turns on, during this time the temperature data is uploaded into the cloud and a discrete sequence plot is done using MATLAB which is also plotted in Thingspeak cloud

\section{B. Working of Temperature control}

The Process parameters that are to be monitored and controlled are $\mathrm{pH}$ value of water and Temperature of the steam that is to be passed on the cloth so that the dye sticks to it. The range within which the temperature is to be maintained is from $60 \mathrm{C}$ to $80 \mathrm{C}$ and for $\mathrm{pH}$ is maintained between 6.5 to 7 in order to keep the water neutral. Since LM35 can operate over a range of $-55^{\circ} \mathrm{C}$ to $150^{\circ} \mathrm{C}$ it is simply enough to monitor the temperature of steam. The initial process is to monitor the temperature data by uploading it to cloud, to accomplish this the temperature sensor is connected to NodeMCU. Though LM35 requires $4 \mathrm{~V}$ to operate, it works well with $3.3 \mathrm{~V}$ provided by NodeMCU the output pin is connected to the only analog input pin of the device. The Program compiled in Arduino IDE for uploading the data into cloud is dumped into the device. For a particular given delay the data is being uploaded to the cloud (Thingspeak). As of now all the collected data is visualized as discrete values of temperature data with respect to time using MATLAB.

\section{Design for $\mathrm{pH}$ control loop}

The circuit diagram for controlling temperature at a specific range is shown below in the figure 3

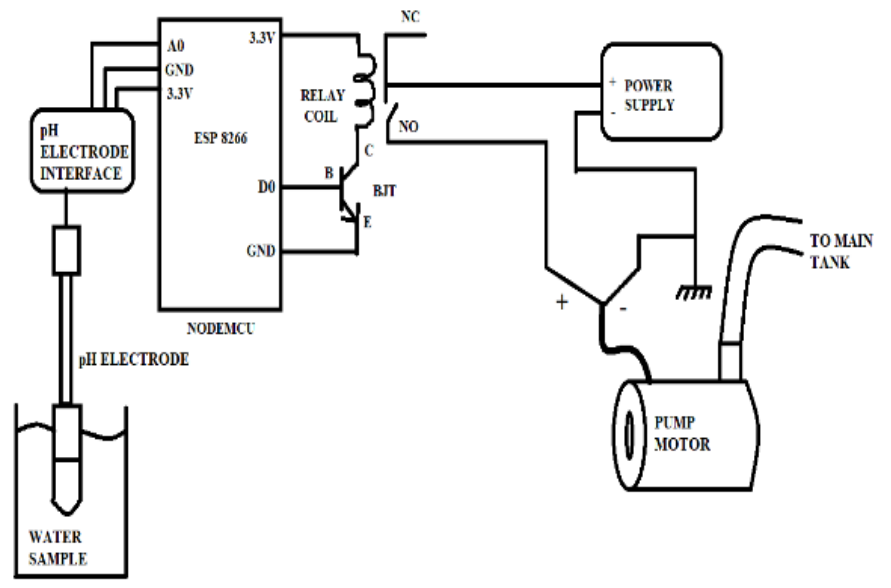

Fig 3. Circuit diagram for $\mathrm{pH}$ control loop

The Digital output pin D0 is made high when the temperature exceeds some value. A Transistor (BJT) acts as a switch here, the base of the BJT is directly connected to the
D0 pin of the NodeMCU. In the collector side a Electromechanical relay is connected by a general supply voltage of $3.3 \mathrm{~V}$ from MCU and the ground terminal connected to the collector. Now whenever D0 is high there is a link between collector and emitter terminal and thus the ground is connected to the GND pin of MCU. So this excites the Relay coil and on the other hand the movable contact of the relay (i.e COM) is given a battery supply of $9 \mathrm{~V}$ to drive a Pump. In the Normally Open terminal the pump is connected. There is normally a small lag after the $\mathrm{pH}$-electrode senses the $\mathrm{pH}$ value and before the pump turns on, during this time the $\mathrm{pH}$ data is uploaded into the cloud and a discrete sequence plot is done using MATLAB which is also plotted in Thingspeak cloud.

\section{Working of pH control}

$\mathrm{pH}$ value is measured through $\mathrm{pH}$-electrode. $\mathrm{pH}$-electrode can able to measure $\mathrm{pH}$ from 2 to 12 with output voltage of 4 to $20 \mathrm{~mA}$. In our project we have to maintain our $\mathrm{pH}$ range from 6.5 to 7 . Measured $\mathrm{pH}$ value is uploaded in a cloud after analysis control action will takes place. Here $\mathrm{pH}$ values are adjusted by adding limited amount of buffer the submersible pump used to carry buffer.

The operator determines the time of chemical additives and the predetermined $\mathrm{pH}$-value depending on its chemical dosage and $\mathrm{pH}$ monitoring requirements. When this is done, the control unit - according to the selected from the chemical characteristics and the $\mathrm{pH}$ target values, the chemical pump so that the mixing valve and the metering valve for the chemicals. The control unit is designed so that it controls the process in the control unit in accordance with a plurality of stored chemical characteristics

\section{RESULT}

Temperature measured from the steam is continuously uploaded in Thinkspeak webpage address .depend upon the temperature value control action is carried out in web page we also upload the status of cooler fan. Through that web the condition of temperature loop are displayed. The figure 6.1 portrays the temperature analysis

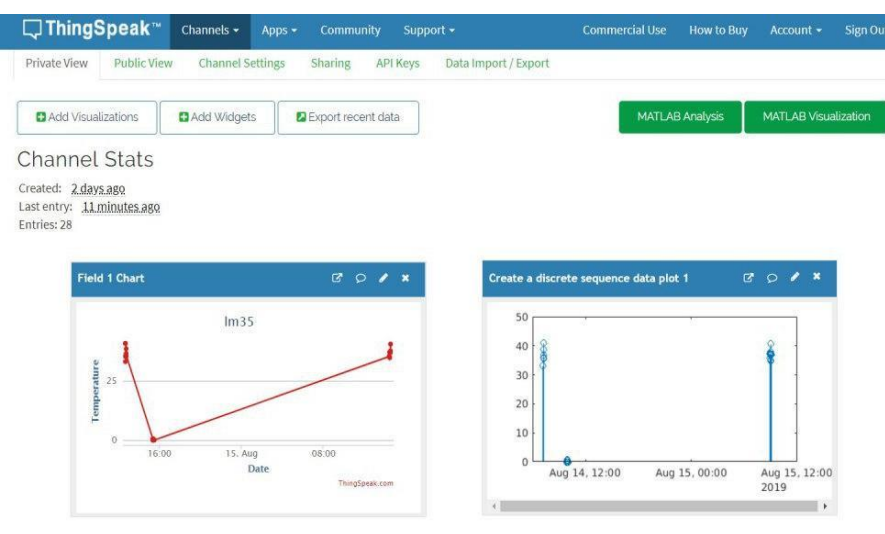

Fig 4. Temperature Analysis 
The temperature value is detected by LM35 sensor and the information are transferred into the cloud and a discrete succession plot is finished utilizing MATLAB which is additionally plotted in Thingspeak cloud. Through this strategy the labor and manual mistake get dodged. The database is displayed in graphical structure. $\mathrm{pH}$ from the underlying shower is estimated using $\mathrm{pH}$ sensor and transferred of the Thingspeak website page constantly. Rely on the $\mathrm{pH}$ worth, control activity is conveyed out in website page. The figure 6.2 shows the transferred information of $\mathrm{pH}$ Analysis.

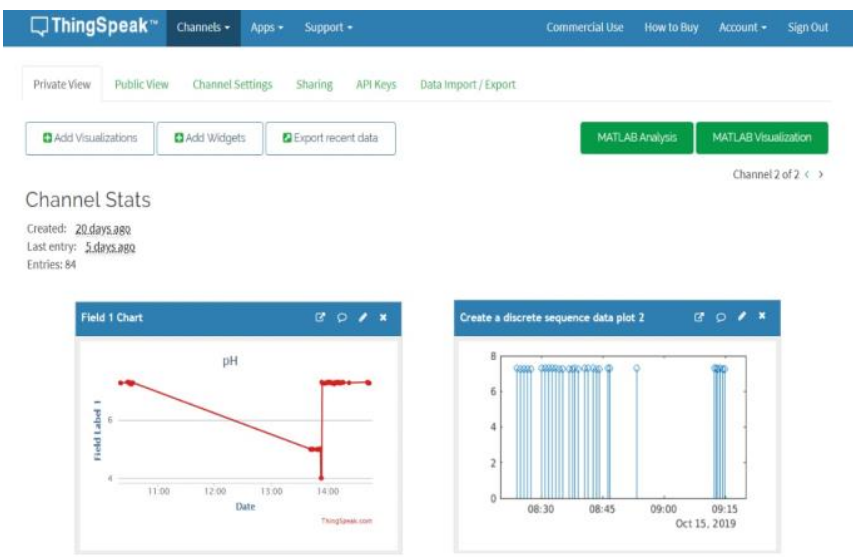

Fig 5. $\mathrm{pH}$ analysis

The $\mathrm{pH}$ electrode detects $\mathrm{pH}$ esteem and the information is transferred into the cloud, a discrete arrangement plot is finished utilizing MATLAB which is additionally plotted in Thingspeak cloud. By execution of this technique we can keep up $\mathrm{pH}$ esteem inside a range. This technique helps in diminishing labor time.

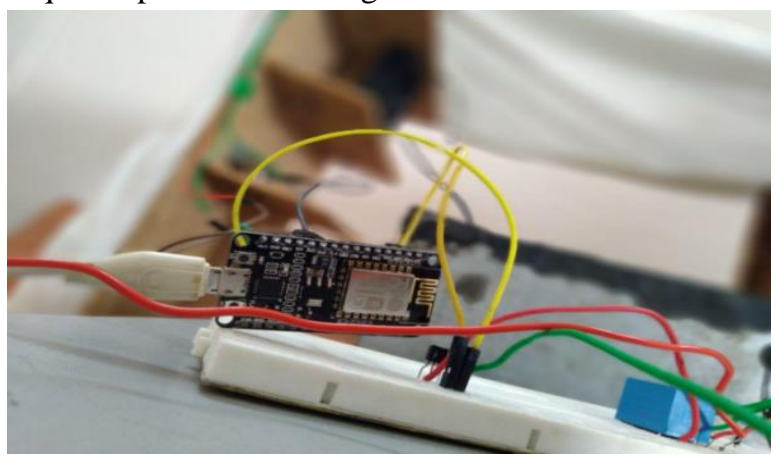

Fig 6. Interface with NodeMcu

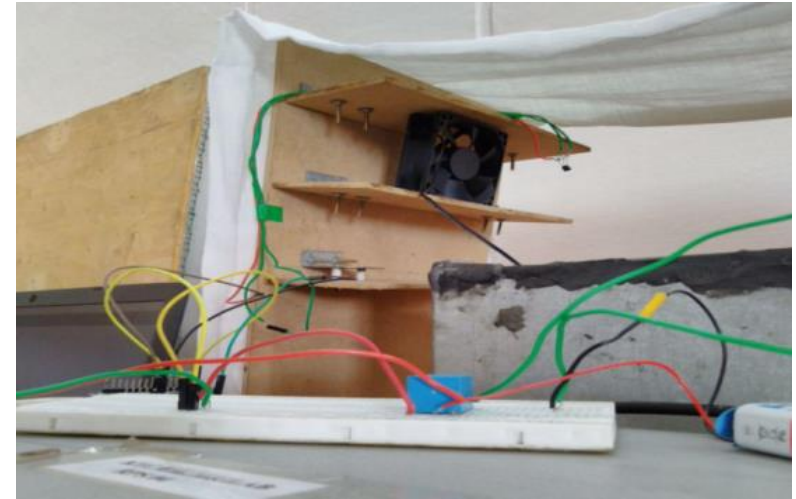

Fig 7. Temperature control loop

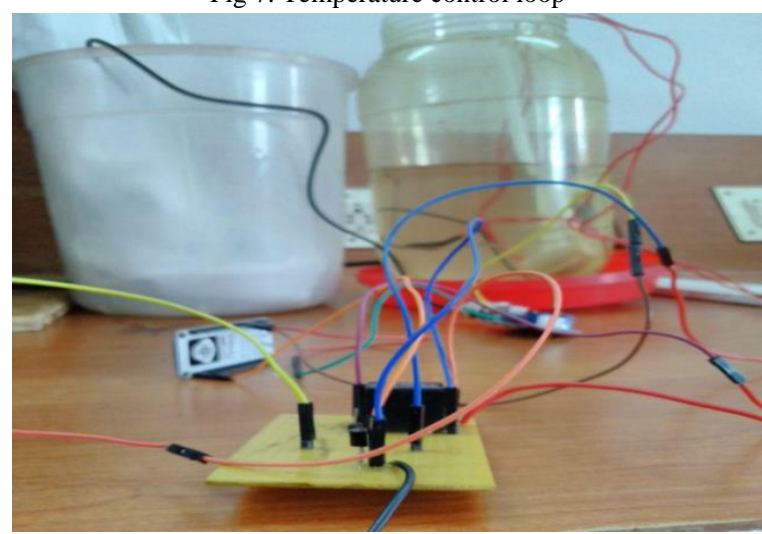

Fig 8. pH control loop

VII. CONCLUSION

In many small dyeing industries and mills around locality of Erode and Tiruppur, the parameters that are required to make the dyeing and fixation process run smoothly are monitored manually through wired networks. The manual operation requires a operator who is incharge of controlling these parameters. In this situation the undefined errors and cable faults are difficult to identify and overcome. Hence the need for wireless technology plays a important role. Moreover the proposed system must be of low capital cost and maintenance cost so that the dyeing mills could take over financially. A common monitoring and controlling domain may relieve them with the need for an operator and take instant actions to overcome or avoid any disturbances that change the nature of the process. Upon these conditions the dyeing firm may adopt to this technology which satisfies both the need for wireless systems and financial problems. The use of wireless node communication has enabled to store the data in the server which can be used for future purpose too, which defines the significance of this proposed system.

\section{FUTURE SCOPE}

Dye sector is one of the core chemical industries in India. The major users of dyes are textiles, papers, plastics, printing ink and foodstuffs. It is also the second highest export in chemical industries. Globally the dyestuff industries has seen an impressive growth. The Indian dyestuff is made up of about 1,000 small units and 50 organised units, who produce around 1,30,000 tonnes of dyestuff. 
These 1,000 small units can be advanced by making the monitoring process to be in wireless mode. There are different parameters that are measured in dye industries. They are monitored in different sectors. The small scale industries are struggling to monitor each parameter separately. By using wireless network we can reduce communication failures and other problems that remain unidentified.

With wireless node communication the parameters can be monitored and controlled in a common domain which will be useful for the small firms to increase their production in an efficient way. As a result small firms can also produce products with high reliability and efficiency.

The future of dye and dyestuff, a part of chemical industry has good prospects in the coming years owing to its high demand. The growth of dye sector in the future will continues to depend on the performance of end user industries like paints, foodstuff etc. The changing customer preferences, boom and expansion of infrastructure in India will create new market opportunities for the dye industry.

\section{REFERENCE}

[1] Andrea Goldsmith, (2005), "Wireless Communications" Stanford University, California.

[2] David TSE and Pramod Vishwanath (2005), "Fundamentals of Wireless Communication" Cambridge University Press.

[3] Matthew Clark (2011), "Handbook of Textile and Industrial Dyeing: Applications of Dyes", Vol.2.

[4] Thomas Browne (2007), "Dyeing and Printing" Basic Dyeing, Batik, Tie Dyeing, Block \& Screen Printing, Linocuts, pp.1-5.

[5] Shamey R. and Zhao X (2014), "Modelling, Simulation and Control of Dyeing Process", A Volume in Woodhead Publishing Series in Textiles, $6^{\text {th }}$ IEEE Conference on Electronics in Industrial Process control.

[6] Jie Fu (2014), "Dyeing Processes, Techniques and its Applications", School of the Environment, Nanjing University, Nanjing, China.

[7] Mansour, Rym \& Mhenni, M.F. \& Ezzili, \& Bechir, M. (2015). "The Journal of The Textile Institute Dyeing Properties of Cationized And Non-Cationized Cotton Fabrics Dyed With Vitis Vinifera L". The Journal of The Textile Institute. Vol.2, pp.5-7.

[8] Liu Qiong (2018). "Research of The Influential Factors and Evaluation Methods of Clothing Thermal-Moisture Comfortable Properties", Textile Dyeing and Finishing Journal, (JIFT), Jiangxi Institute of Fashion Technology 